\title{
A New Approach in Manufacturing of Reverse Vending Machine
}

\author{
M Balubai ${ }^{1}$, VamsikiranSure ${ }^{2}$, V Manil Reddy ${ }^{3}$, Sai Reddy Gowtham ${ }^{4}$, Dr.Ram.Subbiah ${ }^{5}$ \\ ${ }^{1}$ Assistant Professor, Mechanical Department, GRIET Hyderabad, Telengana, India \\ ${ }^{2,3,4}$ B.Tech, Mechanical Department, GRIET, Hyderabad, Telengana, India \\ ${ }^{5}$ Associate Professor, Mechanical Department, GRIET Hyderabad, Telengana, India
}

\begin{abstract}
Reverse vending machine is a concept or an idea which inculcate the habit of recycling the waste materials. Reverse vending machine will be working by taking recyclable waste into the machine and gives a use full thing as a token of appreciation.

The aim of this project is to design and fabricate a reverse vending machine which takes recyclable waste into the machine and displays a token of appreciation. The machine can accept a plastic bottle of $90 \mathrm{~mm}$ diameter without cap and tin cans can be accepted and crushed and stored. The machine has a capacity of storing 50 plastic bottles and 50 tin cans. There basically two parts, one is the mechanical part and the other is the electronics part. The mechanical part is used to crush the recyclable waste which is kept in the machine so that more plastic and cans can be recycled and stored. The electronics part which consist of sensor and microcontroller, is used to take the correct input and segregate the waste into its respective categories and give a token of appreciation as a LCD display. The whole system is automated by the help of electronics. Combining both parts will give a reverse vending machine.

Reverse vending machine will be working by taking recyclable waste into the machine and gives a use full thing as a token of appreciation.

With limited resources in the world, we need to start preserving them and put an end to wastage. Being encouraged to recycle through a rewards system.To encourage recycling process we are designing and manufacturing reverse vending machine.
\end{abstract}

Keywords-Reverse Vending Machine, LCD display, sprocket.

\section{INTRODUCTION}

Presently in India, about 960 million tonnes of solid waste is being generated annually as by-products during industrial, mining, municipal, agricultural and other processes.

However, it's not the amount of waste generated that's as much of an issue as the fact that more than 45 million tonnes, or 3 million trucks worth, of garbage is untreated and disposed of by municipal authorities everyday in an unhygienic manner leading to health issues and environmental degradation.

Reverse vending machine is the solution for recycling the waste.Reverse vending machine will be working by taking recyclable waste into the machine and gives use full thing as output.

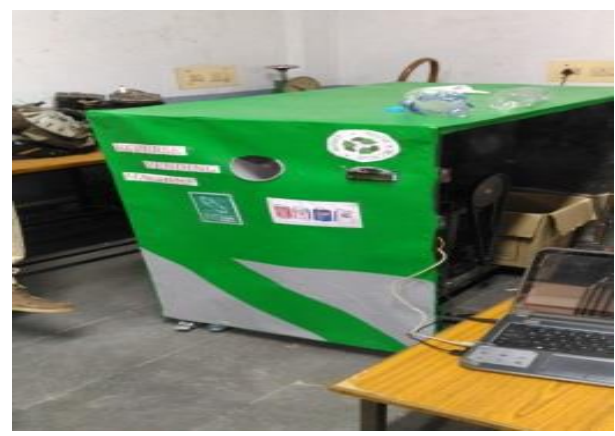

Fig.1: Reverse vending machine

\section{WORKING OF REVERSE VENDING MACHINE}

A reverse vending machine will start working in the following flow. First the waste object is inserted and the LCD display will show the object is detected and tells weather it is a plastic or tin can and it intakes it, the bottle is detected with the help of sensors then the gate is opened if the inserted bottle is plastic or tin can. Then a motor is started and it in turn start rotating the crushing setup which will be used for the volumetric reduction of plastic and tin can then the objects are segregated and dropped into the segregation box , with the help of a segregator and token of appreciation will appear on the LCD display.

\section{PARTS OF REVERSE VENDING MACHINE} 3.1 Motor 
Single phase power system is widely used as compared to three phase system for domestic purpose, commercial purpose and to some extent in industrial purpose. As the single phase system is more economical and the power requirement in most of the houses, shops, offices are small, which can be easily met by single phase system. The single phase motors are simple in construction, cheap in cost, reliable and easy to repair and maintain.

\subsection{Sprockets}

A sprocket or sprocket-wheel is a profiled wheel with teeth, cogs, or even sprockets that mesh with a chain, track or other perforated or indented material. The name 'sprocket' applies generally to any wheel upon which radial projections engage a chain passing over it.

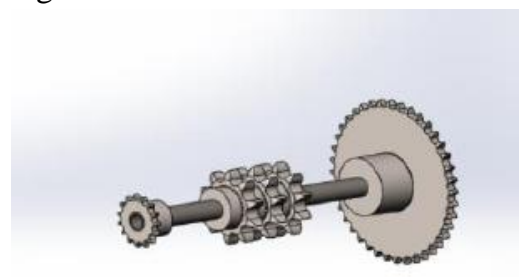

Fig.2: crushing assembly

\subsection{Roller Chain}

Roller chains are used for transmission of mechanical power. It is driven by a toothed wheel called a sprocket. It is a simple, reliable, and efficientmeans of power transmission.

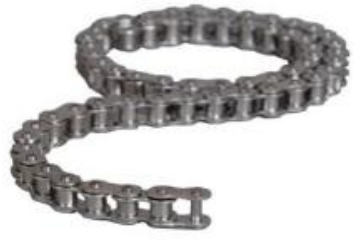

Fig.3: Roller chain

\subsection{Shaft Selection}

The crushing setup is assembled on a shaft i.e., all the sprockets which are used for the purpose for crushing are mounted on a shaft. The shaft which is used is of the material AISI 4130

Dimensions of shaft

Outer Diameter of shaft $=25.4 \mathrm{~mm}$

inner diameter of shaft $=22.4 \mathrm{~mm}$

thickness $=1.5 \mathrm{~mm}$

Length of

shaft $=350 \mathrm{~mm}$.

\subsection{Frame}

A structural frame is a series of connected elements that resist the necessary loads for the whole of the structure and allow the rest of the structure be account for other concerns. The crushing setup is mounted on this SS304 angular frame. On the top of the frame shafts arranged with sprockets are mounted, at the bottom motor is mounted.

3.6.Pedestal Bearings

Pedestal bearings describe a form of housing for bearing units, which belong to the roller bearing group. Roller bearings are bearings, which due to their rolling housings reduce the frictional resistance and are mostly used for fixing axles and shafts. They consist of following components: inner ring, outer ring and the rolling element.

3.7 Cad Model for Crushing Assembly

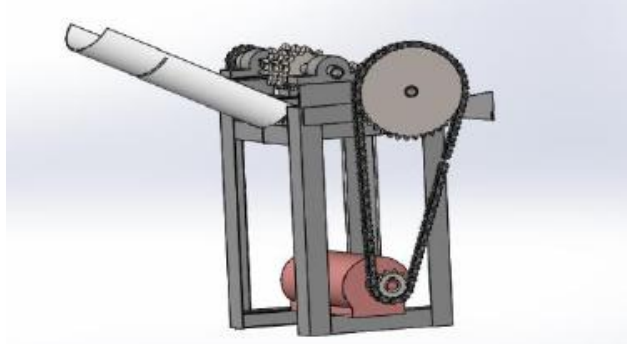

Fig.4: Trimetric View of CAD Model

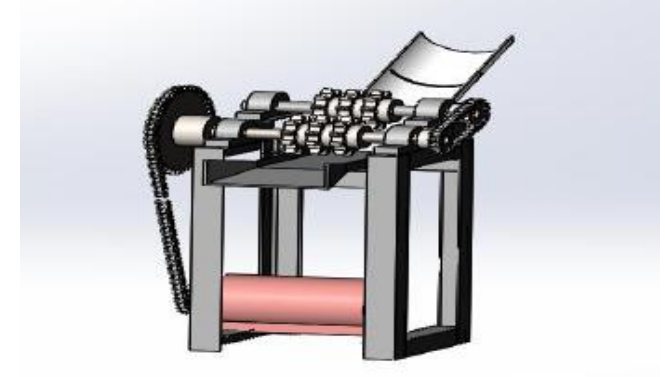

Fig.5: Isometric View - Crushing Assembly.

IV. MANFACTURING OF VENDING MACHINE

Following manufacturing methods were used to fabricate our reverse vending machine.

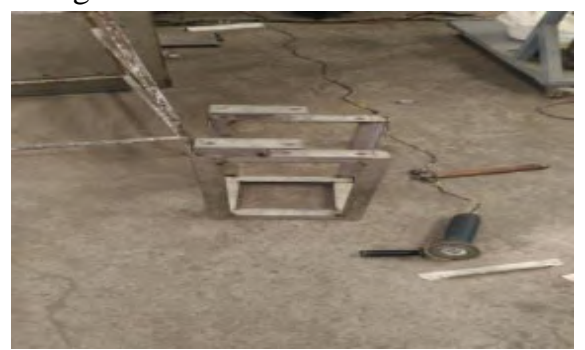

Fig.6:frame of crushing mechanism

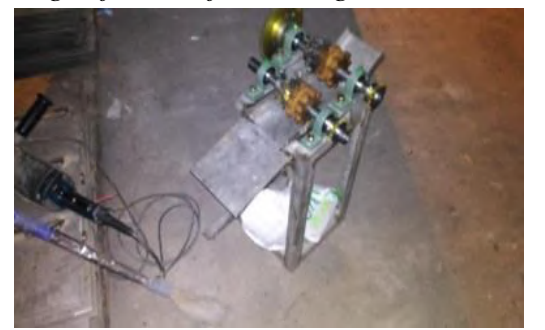


Fig.7: crushing mechanism setup

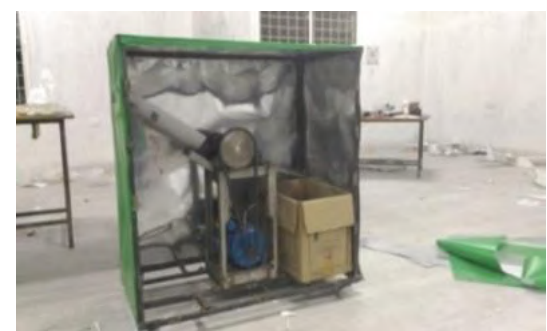

Fig.8: Inside view of Reverse vending machine
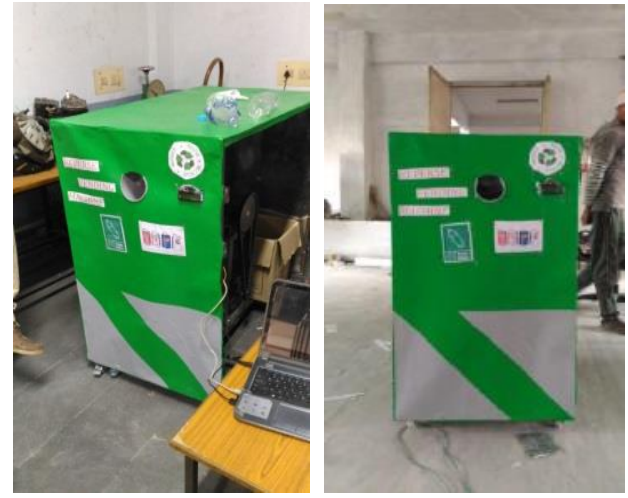

Fig.9: Reverse vending machine

\section{CONCLUSION}

Reverse vending machine has been designed and manufactured, for the immediate segregation of recyclable waste. Volumetric reduction of the materials done for better storage capacity and handling. The machine is capable of collecting two kinds of trash i.e., plastic bottles and tin cans and stores up to 100 no's , 50 each respectively. Economic feasibility of the project is evident from the price range of the already available machine in the market.

We have reduced the cost of the machine by $85 \%$. Our objective has been achieved based on the parameters that are considered have been accomplished.

The capacity of the machine can also be increased by various process such as increasing the container volume, increasing the number of intake ports .

\section{REFERENCES}

[1] Allen, J. Davis, \&Soskin. (1993). Using coupon incentives in recycling aluminum:A Market Approach to Energy Conservation Policy. The Journal of Consumer Affairs, Volume 27, 300.
[2] Bannatyne, R. and Viot, G. (1997). Introduction to Microcontrollers. Journal of IEEE, 0-7803-4303-4.pg 564-574

[3] Leong,S.L, (1998, April 26).Promoting Recycling Culture. The New Straits TimesPress.

[4] Leuder, E. (2003). Liquid Crystal Display.John Wiley\& Sons, Ltd.

[5] Muhammad Tarmizi Lockman, Ali Selamat (2008). "Verification and Validation Communication Layer of Embedded Smart Card System.’Universiti Teknologi Malaysia: Thesis Bachelor Of Degree.

[6] Rankl, Wolfgang. (2010). Smart Card Handbook (4th ed.). John Wiley and Sons, Ltd

[7] Return Recycling News, (2005). Retrieved March 29, 2011, fromhttp://www.tomra.com

[8] Benefits of Smart Cards. (2000). Retrieved March 22, 2011, fromhttp://www.buzzle.com/articles/benefits-ofsmart-cards.html

[9] Reverse Vending Machine [Brochure]. (2009). Retrieved from Reverse Vending Corporation. website: http://www.reversevending.co.uk/

[10] Smart Card Basics. (2010). Retrieved March 21, 2011, from Card Logix Corporation website: http://www.smartcardbasics.com/smart-cardoverview.html 